\title{
Measuring Disease Activity and Damage with Validated Metrics: A Systematic Review on Mortality and Damage in Systemic Lupus Erythematosus
}

\author{
Stephanie O. Keeling, Ben Vandermeer, Jorge Medina, Trish Chatterley, Tatiana Nevskaya, \\ Janet Pope, Zainab Alaburubalnabi, Asvina Bissonauth, and Zahi Touma
}

\begin{abstract}
Objective. To identify the effect of disease activity and damage, measured by validated indices, on mortality and damage accrual, in order to inform upcoming Canadian systemic lupus erythematosus (SLE) recommendations.

Methods. Following GRADE (Grading of Recommendations Assessment, Development and Evaluation) methodology to fill in evidence-to-decision tables to create recommendations for "minimal investigations needed to monitor SLE patients at baseline and subsequent visits," a systematic literature review was performed. The effect of disease activity and damage, measured by validated metrics, on mortality and damage was systematically reviewed, with metaanalyses performed when available.

Results. A title/abstract screen of 5599 articles identified 816 articles for full paper review, with 102 meeting inclusion criteria and 53 with extractable data. Thirty-three articles describing outcomes related to disease activity and 20 articles related to damage were identified. Mortality was associated with higher SLE Disease Activity Index-2000 scores in 6 studies (HR 1.14, 95\% CI 1.06-1.22) and higher Systemic Lupus International Collaborating Clinics/ACR Damage Index scores in 6 studies (HR 1.53, 95\% CI 1.28-1.83). Higher SLE Activity Measure scores were associated with increased risk of damage in 3 studies (OR 1.06, 95\% CI 1.04-1.08). British Isles Lupus Assessment Group was associated with mortality in 1 study with HR of 1.15 .

Conclusion. Active SLE disease and damage are associated with and predict greater mortality and damage. The use of validated disease activity and damage metrics is important in the assessment of disease activity and damage and will inform upcoming Canadian recommendations for the assessment of SLE. (First Release August 15 2018; J Rheumatol 2018;45:1448-61; doi:10.3899/jrheum.171310)
\end{abstract}

Key Indexing Terms:

SYSTEMIC LUPUS ERYTHEMATOSUS

DISEASE ACTIVITY

DISEASE DAMAGE

MORTALITY

From the Division of Rheumatology, Department of Medicine, and the Alberta Research Centre for Health Evidence, and the John W. Scott Health Sciences Library, University of Alberta, Edmonton, Alberta; Division of Rheumatology, Department of Medicine, Institute of Health Policy, Management and Evaluation, University of Toronto, Toronto; Division of Rheumatology, Department of Medicine, University of Western Ontario, London, Ontario; Division of Rheumatology, Department of Medicine, University of British Columbia, Vancouver, British Columbia, Canada.

This work was supported partly by a dissemination event grant from the Canadian Institute of Health Research and a meeting grant from the Arthritis Society of Canada.

S.O. Keeling, MD, MSc, FRCP(C), Associate Professor, University of Alberta; B. Vandermeer, MSc, Biostatistician, Alberta Research Centre for Health Evidence, University of Alberta;

T. Chatterley, MLIS, Librarian, John W. Scott Library, University of Alberta; T. Nevskaya, $M D, P h D$, Internal Medicine Resident, University of Western Ontario; J. Pope, MD, FRCP (C), Professor of Medicine, University of Western Ontario; Z. Alaburubalnabi, MBBS, ABIM, FRCPC, Assistant Professor, University of British Columbia; A. Bissonauth, MRes, Research Coordinator, University of Alberta; Z. Touma, $M D, P h D$, Assistant Professor, University of Toronto. Jorge Medina died February 4, 2018.

Address correspondence to Dr. S.O. Keeling, 8-129 Clinical Sciences Building, University of Alberta, Edmonton, Alberta T6G 2G3, Canada. E-mail:stephanie.keeling@ualberta.ca
Full Release Article. For details see Reprints and Permissions at jrheum.org

Accepted for publication June 23, 2018.

Systemic lupus erythematosus (SLE) is a complex autoimmune disease that includes targeted autoantibody production, resulting in heterogeneous disease phenotypes ${ }^{1}$. Manifestations vary considerably, requiring careful in-depth clinical assessments to clearly define the degree of disease activity. Disease damage is another important domain in the assessment of patients with SLE, driven both by the burden of disease activity, glucocorticoids, and immunosuppressant exposure $^{2}$. As a result, the contribution of both disease activity and damage leading toward further damage and mortality in SLE is increasingly recognized by physicians treating SLE.

Despite the important relative contributions of disease activity and damage toward SLE outcomes, clinical assessment of patients varies among rheumatologists. Formalized assessments with the use of validated outcome measures of disease activity and damage are largely

Personal non-commercial use only. The Journal of Rheumatology Copyright $(\subset) 2018$. All rights reserved 
performed in tertiary care centers that are systematically collecting SLE outcomes for research. A practice pattern survey of Canadian rheumatologists revealed that most were not formally evaluating disease activity or damage using standardized metrics [e.g., validated disease activity instruments such as the SLE Disease Activity Index (SLEDAI)] ${ }^{3}$. This is in contrast to other rheumatic diseases such as rheumatoid arthritis (RA) or spondyloarthritis (SpA), in which validated composite measures of disease activity have been integrated more commonly into clinical practice to facilitate treat-to-target care and medication reimbursement.

Recommending regular performance of validated measures of SLE disease activity and damage in clinical practice is complicated because of many factors including appropriateness in the clinic setting and rheumatologists' familiarity with available instruments. Moreover, the association between the measured constructs in these validated measures and the important physician-driven outcomes of mortality and damage in the short term and long term require analysis. Therefore, the goal of this systematic literature review was to collect existing evidence for the effect of disease activity and damage when measured with validated metrics on mortality and damage in patients with SLE. This summary of evidence will inform upcoming Canadian recommendations for the assessment of SLE using the GRADE (Grading of Recommendations Assessment, Development and Evaluation) methodology.

\section{MATERIALS AND METHODS}

A survey of 175 Canadian rheumatologists to evaluate practice patterns for the diagnosis, monitoring, and treatment of patients with SLE was completed in 2012 and served as the basis for future Canadian SLE recommendations ${ }^{3}$. The question of disease activity/damage evaluation as part of patient assessment/monitoring over time arose from this survey, serving as the basis for this systematic literature review. Patient-reported outcomes (PRO) were not included in this analysis owing to the heterogeneity of outcome measures, and difficulties applying this in a clinical context, knowing that PRO and disease activity/damage are independent domains in the assessment of SLE and in general not associated with disease activity/damage. Moreover, disease flares were discussed but not included in the measured outcomes because of the difficulties in finding homogeneous definitions among studies.

Search strategy. The effects of disease activity and damage, using validated metrics, on the outcomes of damage accrual [measured by the Systemic Lupus International Collaborating Clinics/American College of Rheumatology Damage Index (SDI)] and mortality were assessed. A list of candidate disease activity and damage measures was identified by the group through the American College of Physicians ${ }^{4}$ Journal Club, UptoDate, and existing systematic reviews on the subject. A final list of candidate measures of disease activity/damage was circulated and discussed by teleconference by the group and submitted to the librarian (TC) as part of the search criteria. Relevant articles were identified by searching OVID Medline (1946 to July 2016), OVID Embase (1974 to July 2016), and the Cochrane Library (inception to July 2016). Conference abstracts retrieved from Embase were also reviewed. The search strategy was broad to address 2 PICO (population, intervention, comparison, outcome), the first relating to validation studies for disease activity and damage measures (not the subject of this review). The second PICO and focus of this review evaluated the following: population $=$ SLE; intervention $=$ disease activity and damage scores; comparison = self; outcome $(\mathrm{s})=$ worse disease activity, damage, and mortality.

Terms were searched as keywords and/or subject headings as appropriate (Supplementary Data 1, available with the online version of this article) and duplicate references were removed within RefWorks. Studies were limited to those involving humans, and exclusions included non-English abstracts, case reports, editorials, and review articles. Bibliographies of review and guideline articles were hand-searched for articles meeting the inclusion criteria. The dataset from this search was used to inform GRADE recommendations for SLE assessment and monitoring in Canada. Ethics approval was not required because this was a systematic literature review.

Data collection and analysis. Title/abstract screening was performed by 2 reviewers (SOK/AB) and full paper review divided among SOK/JM/ZT/NT/ $\mathrm{JP} / \mathrm{ZA} / \mathrm{AB}$. Disagreements at the title screening and full paper level were discussed and consensus reached. A prespecified Excel spreadsheet for inclusion/exclusion criteria and data extraction was created to reduce data extraction error. Data extraction included publication information (year/author), study site(s), study design, patient population, sample size, outcome measure(s) used (e.g., specific disease activity or damage measure), comparator measures, and outcomes assessed [mortality, damage (free text for specific damage data)].

Data analyses included descriptive statistics. Mortality and damage outcomes were pooled using a DerSimonian Laird random effects model when enough data were available for studies using validated disease activity and damage measures (BV). The statistical heterogeneity was assessed with the $\mathrm{I}^{2}$ test statistic with the following interpretations: $25-49 \%$ low heterogeneity; $50-74 \%$ moderate, and $\geq 75 \%$ high heterogeneity ${ }^{5}$. Pooled relative risks (RR) and OR with $95 \%$ CI comparing dead versus surviving patients with higher disease activity and damage were also calculated. Data from cohorts with multiple studies were included only once. Study quality was assessed using the Newcastle-Ottawa scale for observational studies ${ }^{6}$.

\section{RESULTS}

We identified 816 papers for full review. Fifty-three met the specific inclusion criteria for mortality and damage outcomes from high disease activity or damage scores after removing 33 for evaluating PRO (e.g., the Medical Outcomes Study Short Form-36 questionnaire, fatigue). These were the most common reasons for data exclusion: (1) not meeting the inclusion criteria (664 articles); (2) not being in English (18 articles); (3) being reviews (14 articles); and (4) involving rheumatic diseases other than SLE (14 articles). Thirty articles described outcomes related to disease activity measures [British Isles Lupus Assessment Group (BILAG), SLEDAI, European Consensus Lupus Activity Measure (ECLAM), and SLE Activity Measure (SLAM)] and 23 related to damage measures (SDI and Brief Index of Lupus Damage; Figure 1) ${ }^{7}$.

Disease activity outcome measures. Four different disease activity measures were evaluated (Table $1^{8-61}$ ) including the BILAG index, the SLEDAI and its derivations [SLEDAI-2K, Safety of Estrogens in Lupus Erythematosus National Assessment (SELENA)-SLEDAI, Mexican SLEDAI], with 30 studies in total. The majority (23) of studies were prospective, 9 were retrospective, 1 study was from a randomized control trial, 1 from an SLE clinical trials registry, and 2 were observational cohorts not otherwise specified. Higher mortality was noted in 6 studies ${ }^{14,22,23,35,37,38}$ evaluating the effect of higher SLEDAI scores at baseline or over time (weight-adjusted HR

Personal non-commercial use only. The Journal of Rheumatology Copyright @ 2018 . All rights reserved. 


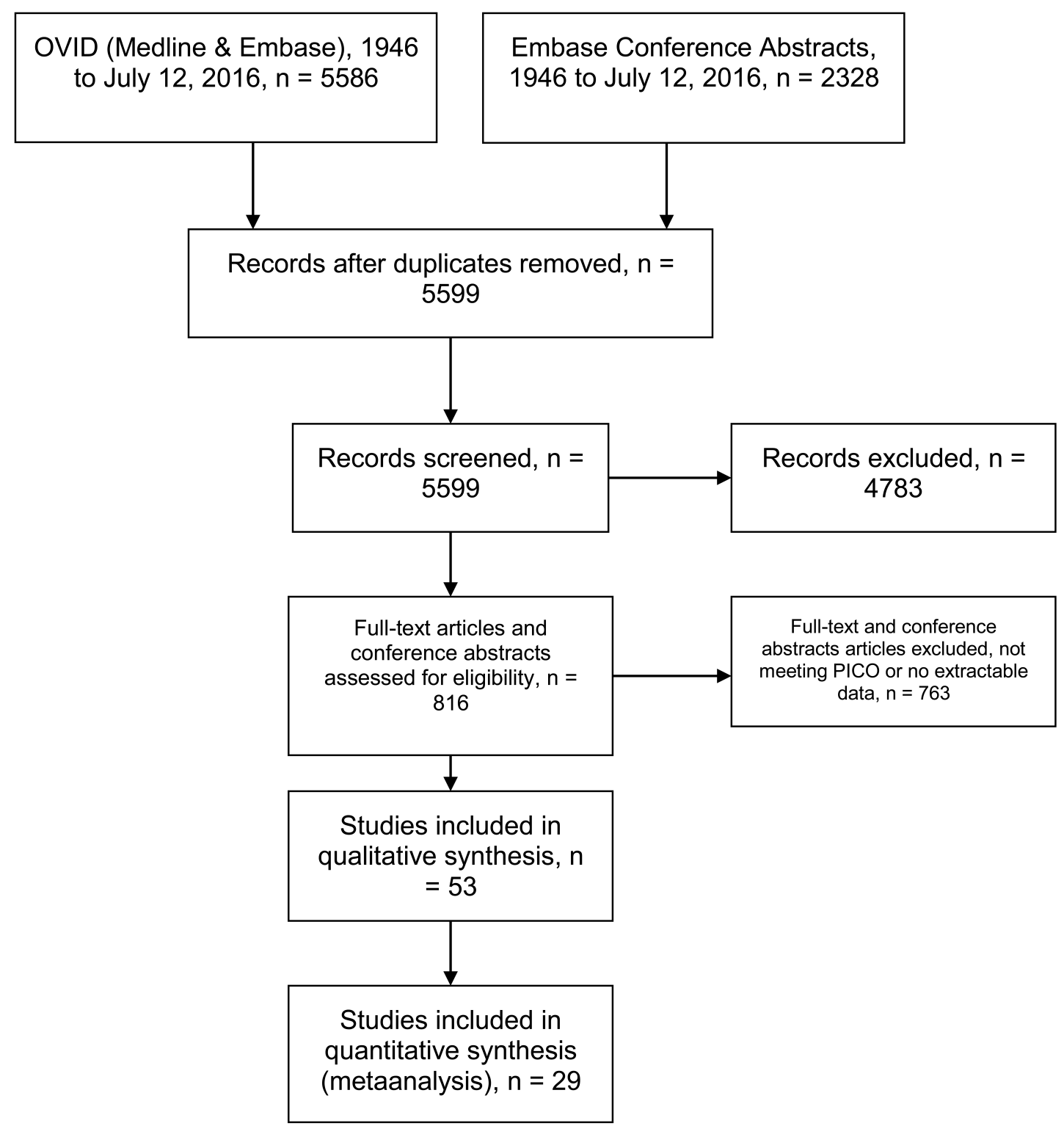

Figure 1. PRISMA diagram for systematic literature review and metaanalysis. PRISMA: Preferred Reporting Items for Systematic reviews and Meta-Analyses; PICO: population, intervention, comparison, outcome. From: Moher D, Liberati A, Tetzlaff J, Altman DG, The PRISMA Group (2009). Preferred Reporting Items for Systematic Reviews and Meta-Analyses: The PRISMA statement. PLoS Med 2009;6(7):e1000097. Distributed under the terms of the Creative Commons Attribution License.

$1.14,95 \%$ CI 1.06-1.22; Figure 2). Sensitivity analyses evaluating the effect of higher baseline SLEDAI and higher time-adjusted SLEDAI [e.g., adjusted mean SLEDAI (AMS)] on mortality demonstrated a greater but not statistically significant mortality risk, with HR of 1.13 (95\% CI 0.99-1.28) for baseline SLEDAI ${ }^{35,37,38}$ and HR 1.19 (95\% CI 0.99-1.43) for time-adjusted SLEDAI (data not shown) ${ }^{14,20,21,22,23}$.

A greater risk of mortality was found in patients with SLE with over 10 years of followup ${ }^{14,22,23,38}$ (HR 1.13, 95\% CI $1.06-1.21)$ compared to those with $<10$ years of followup $^{35,37}$ in a sensitivity analysis (HR $1.98,95 \%$ CI $0.53-7.49$ ). Although increasing age is a significant risk factor for mortality, the majority of these patients were young adults, in whom the relative contribution of age to death is less significant. Three studies (Figure 2) demonstrated higher SLEDAI scores in dead versus living patients with $\mathrm{SLE}^{29,32,39}$, and the odds of mortality were greater (OR 1.13, 95\% CI 1.06-1.22) in SLE patients with higher SLEDAI disease activity ${ }^{25}$.

Higher disease activity scores were also associated with greater damage in patients with SLE (Figure 3). Three studies ${ }^{18,24,25}$ demonstrated greater damage in patients with higher SLEDAI scores at baseline with OR 1.08 (95\% CI 1.03-1.12; Figure 3). Four studies ${ }^{14,15,21,30}$ demonstrated 


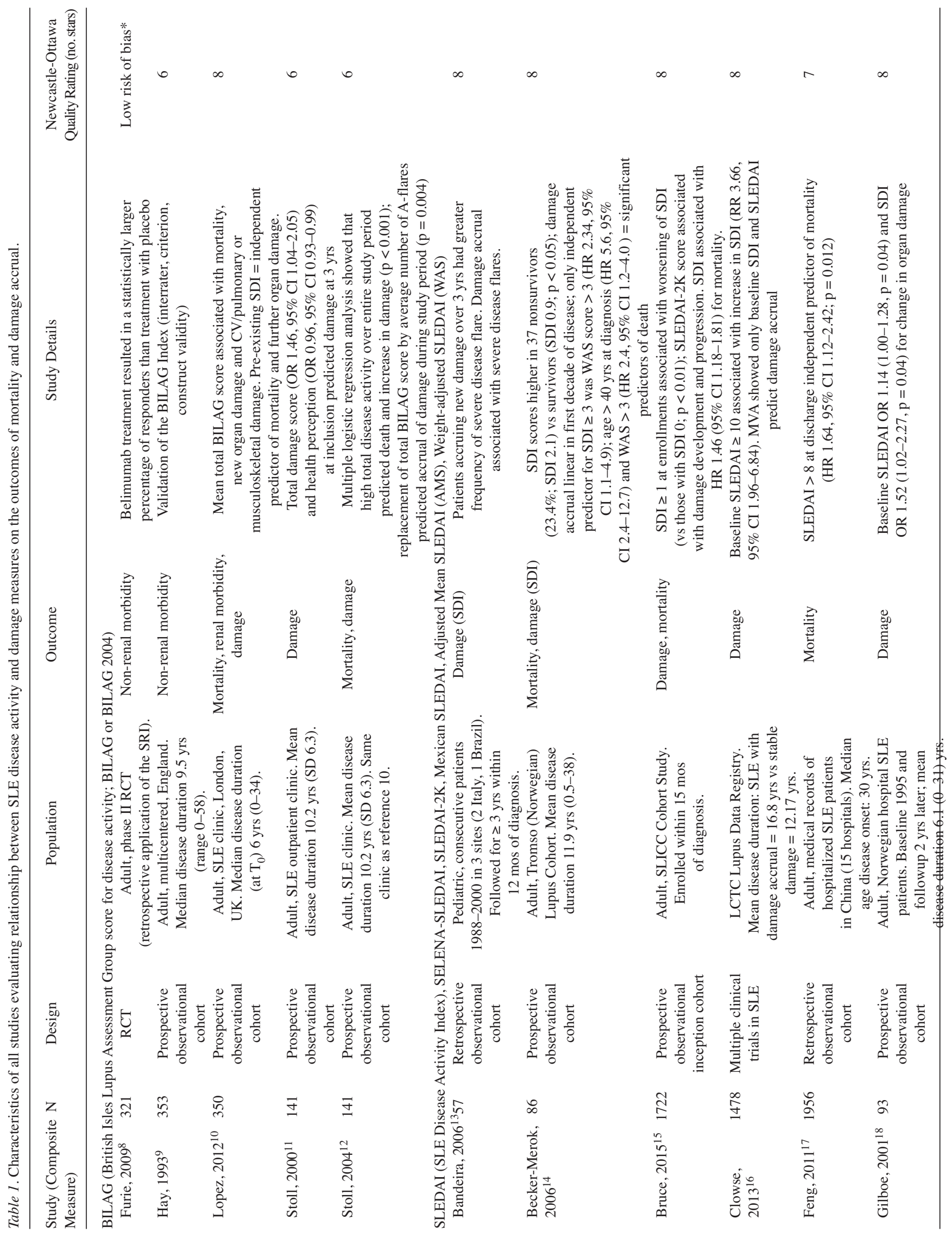

Personal non-commercial use only. The Journal of Rheumatology Copyright (C) 2018. All rights reserved. 


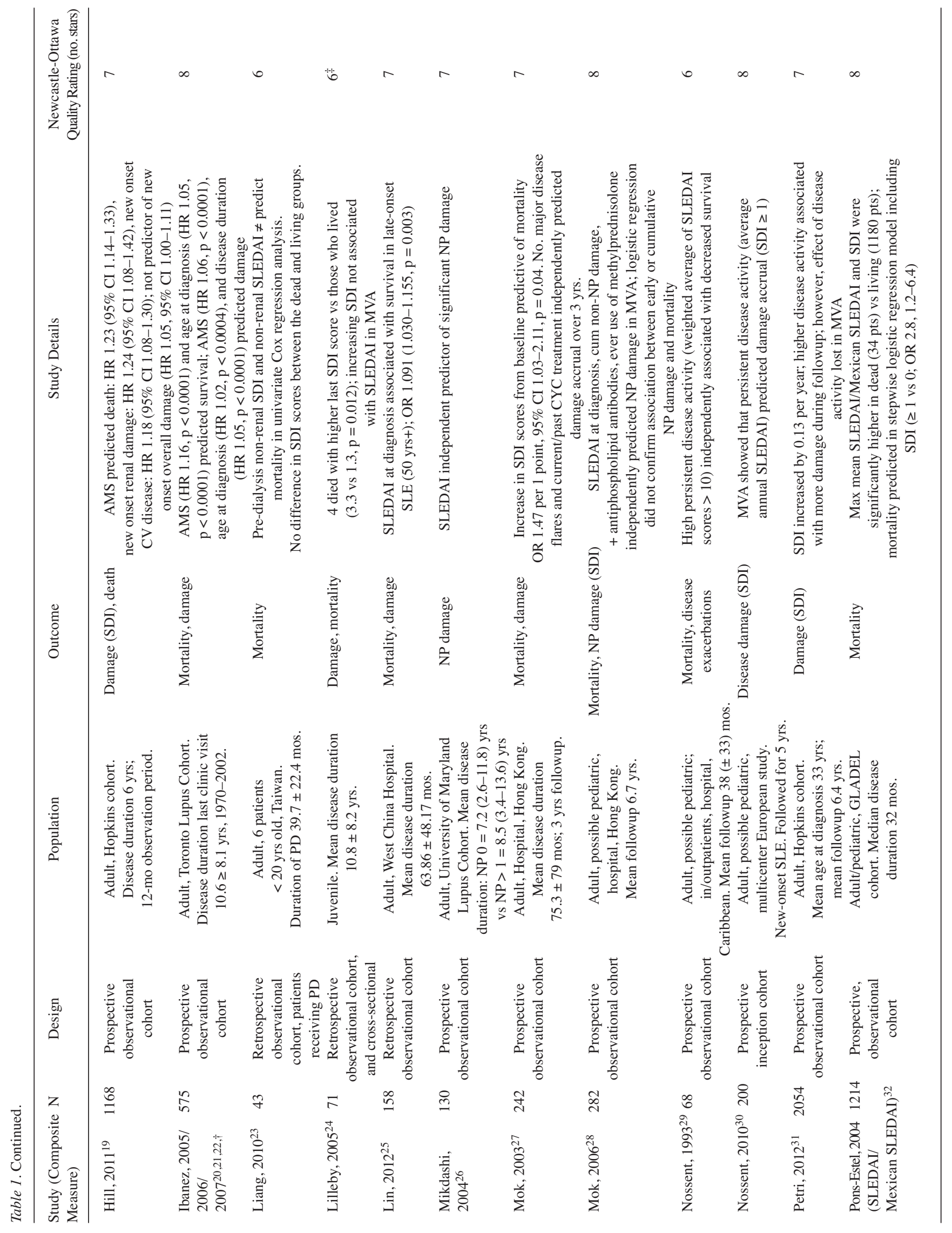

Personal non-commercial use only. The Journal of Rheumatology Copyright (c) 2018. All rights reserved. 


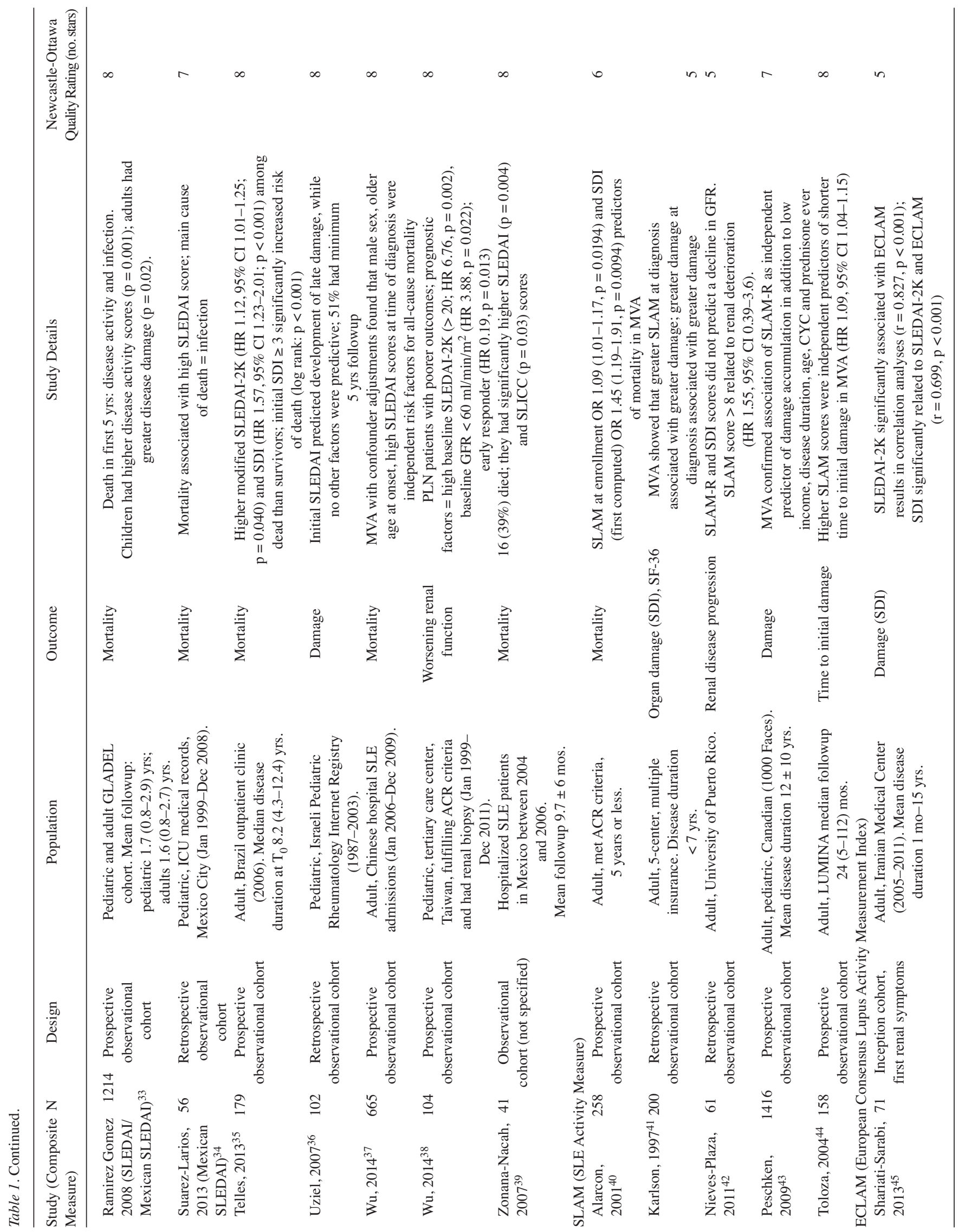

Personal non-commercial use only. The Journal of Rheumatology Copyright ()$_{2018}$. All rights reserved. 


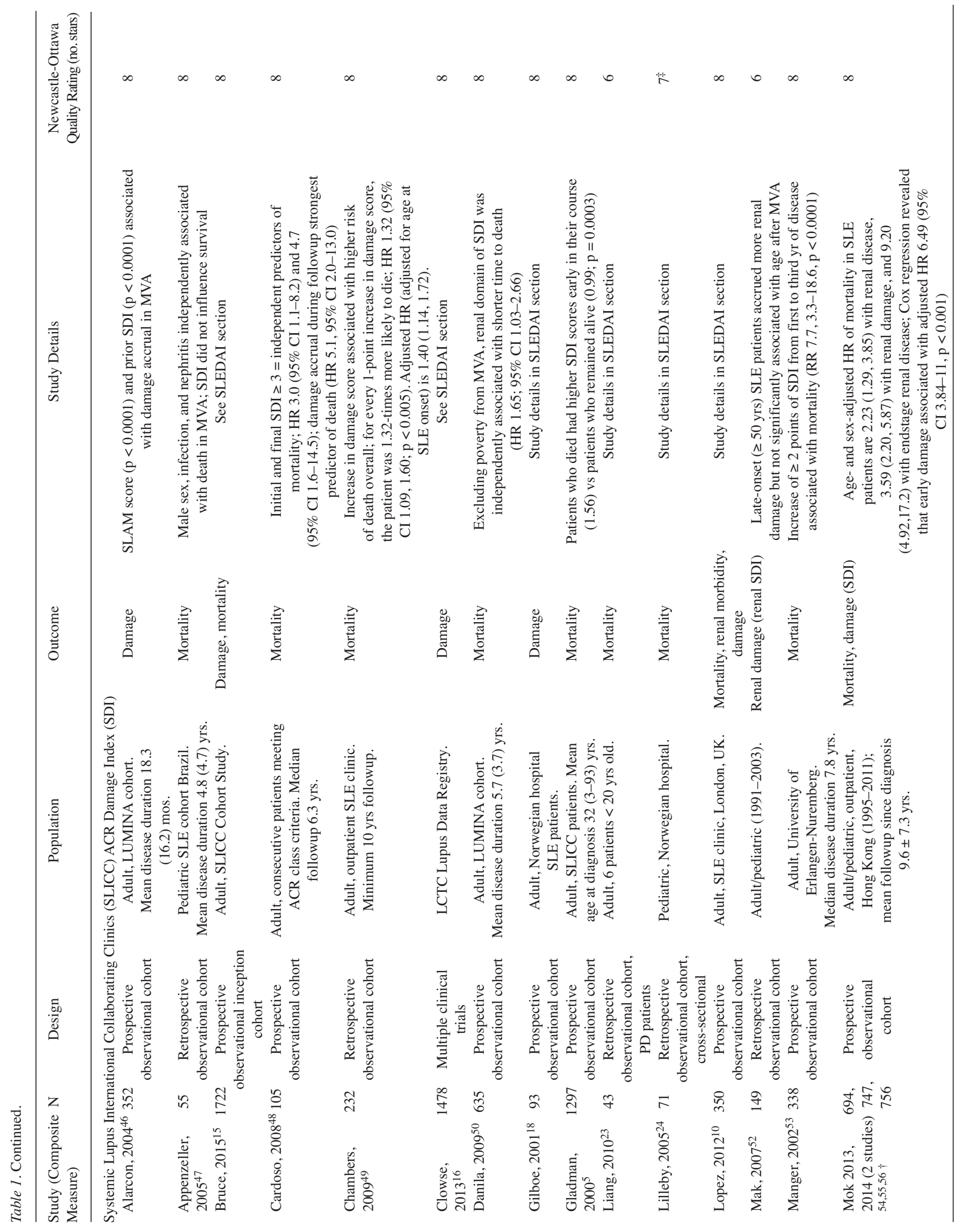

Personal non-commercial use only. The Journal of Rheumatology Copyright (c) 2018. All rights reserved. 


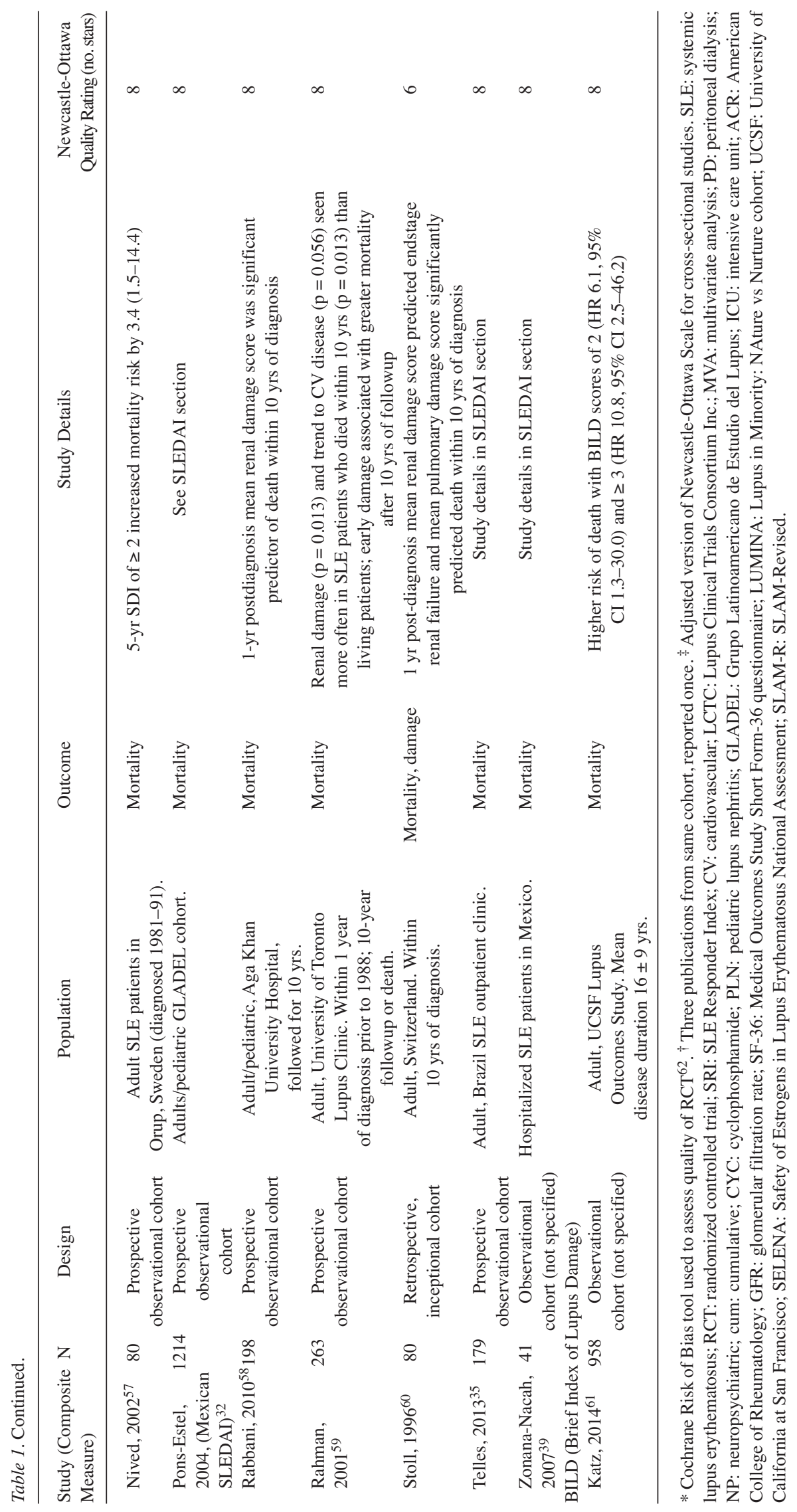

Personal non-commercial use only. The Journal of Rheumatology Copyright $\odot$ 2018. All rights reserved. 


\section{HR for risk of mortality with higher scores at baseline and over time.}

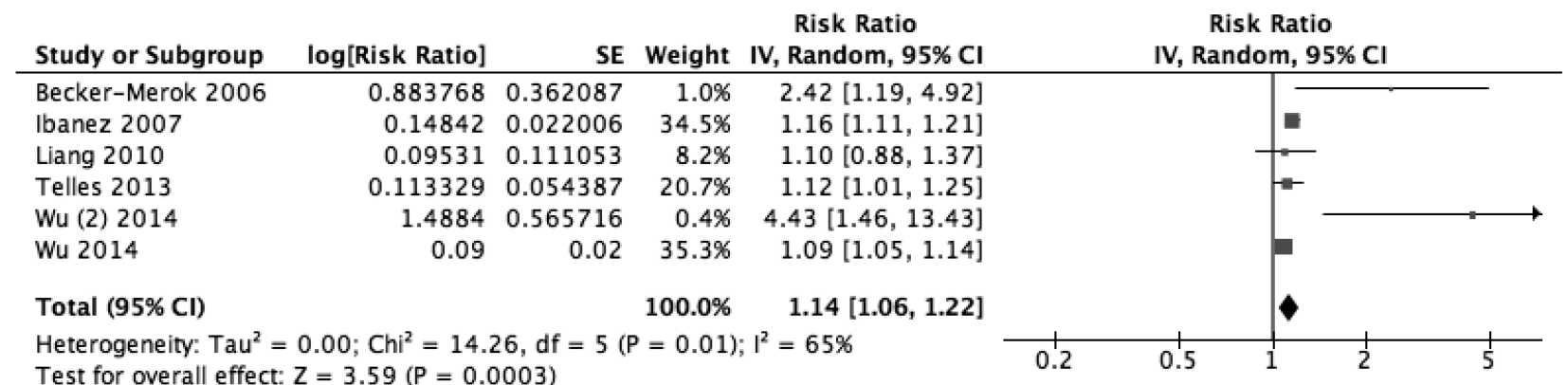

\section{Mean difference between dead and living SLE patients with higher SLEDAI scores.}

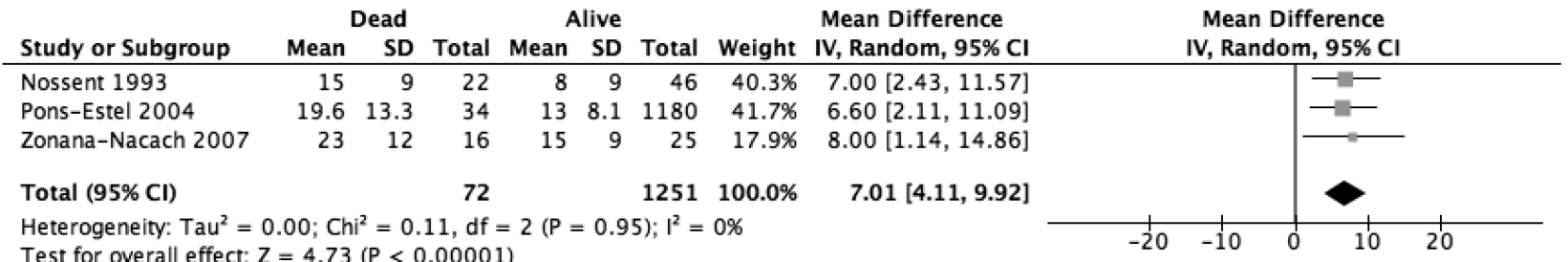

Figure 2. Forest plots depicting the risk of mortality with higher SLEDAI scores. SLE: systemic lupus erythematosus; SLEDAI: SLE Disease Activity Index.

greater risk of damage in patients with higher SLEDAI scores over time with HR 1.18 (95\% CI 1.02-1.37). A sensitivity analysis evaluating 2 inception cohorts ${ }^{15,30}$ identified an HR of 1.23 (95\% CI 1.15-1.32) for damage accrual associated with higher SLEDAI over time. Higher SLEDAI scores appeared to affect neuropsychiatric damage in 2 studies $^{26,28}$ (Figure 3). Stoll, et al ${ }^{12}$ demonstrated that worse BILAG scores increased the odds of damage (OR 1.62, 95\% CI 1.22-2.16), while Lopez, et $a l^{10}$ also found a greater risk of damage with worse BILAG scores. Three studies ${ }^{41,43,46}$ demonstrated the effect of worse SLAM scores on damage (HR 1.06, 95\% CI 1.04-1.08; Figure 3). Toloza, et al ${ }^{44}$ demonstrated a significant difference in the SLAM scores of SLE patients with damage versus those without damage.

Many other studies could not be combined to produce meaningful metaanalyses; however, those studies that involve pediatric and adult SLE international cohorts in both outpatient and hospital settings do support the association between higher disease activity (using SLEDAI, Mexican SLEDAI, BILAG, SLAM, or ECLAM) and the outcomes of mortality and damage accrual, respectively (Table 1). For example, in the Hopkins Lupus Cohort, AMS was a significant independent predictor of mortality (HR 1.23, 95\% CI 1.14-1.33) ${ }^{19}$. Hospitalized Chinese patients with SLE had a higher mortality (HR 1.64) when discharged with a SLEDAI $>8^{17}$, while a higher SLEDAI at diagnosis for a retrospective Chinese cohort of late-onset SLE (50 yrs or older) was an independent predictor of mortality (OR 1.091, $\mathrm{p}=0.003)^{25}$. In confirming that the SDI score increased by 0.13 per year, Petri, et al also demonstrated that damage risk was greater for patients with higher disease activity (SELENA-SLEDAI); however, this association was not significant after adjusting for corticosteroid use ${ }^{31}$.

SLE damage measures. The majority of studies evaluating the effect of damage on mortality and further damage involved the SDI (22 studies), with 14 prospective and 6 retrospective observational cohorts, 1 clinical trial registry, and 2 observational studies not otherwise specified. Specifically, 7 studies ${ }^{10,15,35,48,49,55,59}$ found a significant effect on mortality with worse damage as measured by the SDI either at baseline or over time (HR 1.44, 95\% CI 1.29-1.61; Figure 4). Sensitivity analyses were performed evaluating the effect on mortality of damage (measured by the SDI) at baseline and over time and confirmed HR of 1.35 (95\% CI 1.25-1.46) and 1.57 (95\% CI 1.29-2.11), respectively (data not shown). Four studies ${ }^{23,32,39,51}$ demonstrated worse SDI in dead versus living patients; however, the data were statistically insignificant (Figure 4). Although this was not statistically significant, the sample size and the heterogeneity of the included studies (as demonstrated by $\mathrm{I}^{2}=44 \%$ ) could have affected these results. In addition, 2 studies ${ }^{18,46}$ independently demonstrated greater odds of early damage in patients with baseline damage (worse SDI scores); however, the statistical effect was lost in the metaanalysis (OR 1.20,

Personal non-commercial use only. The Journal of Rheumatology Copyright @ 2018 . All rights reserved. 
OR for accruing damage based on the SLEDAI at baseline.

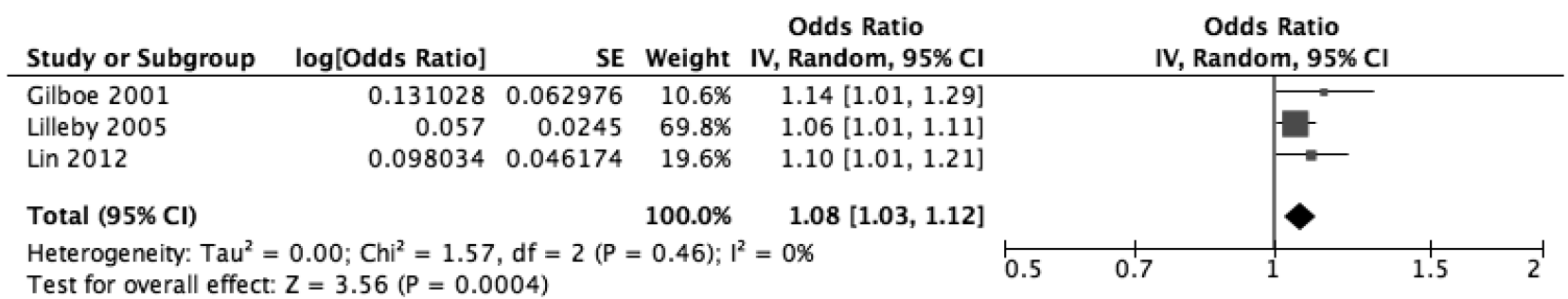

\section{HR measuring the effect of the SLEDAl over time on the outcome of damage accrual.}

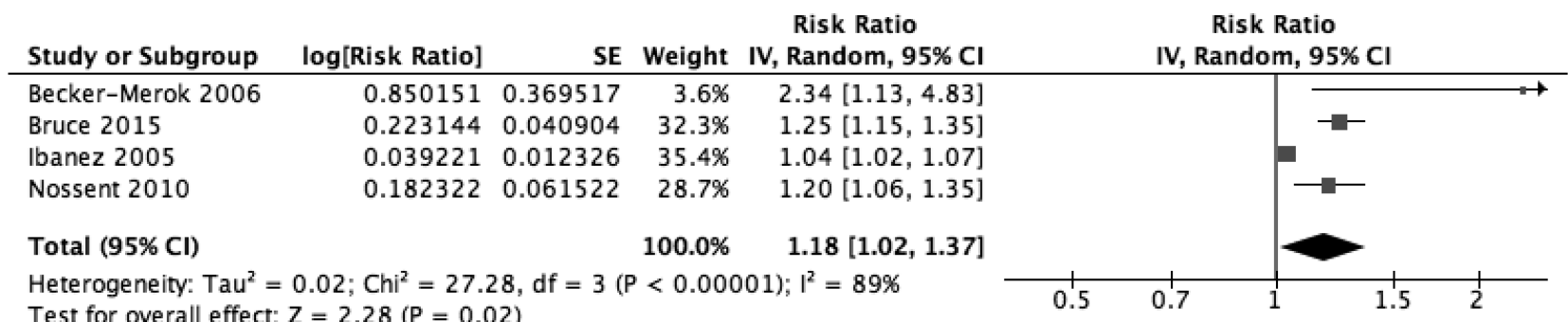

\section{OR for neuropsychiatric damage based on the SLEDAI score.}

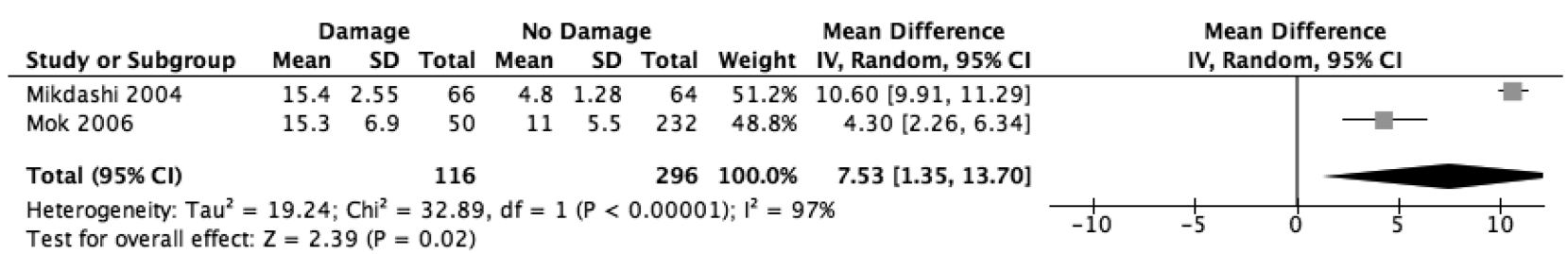

\section{OR for damage accrual based on the SLAM score.}

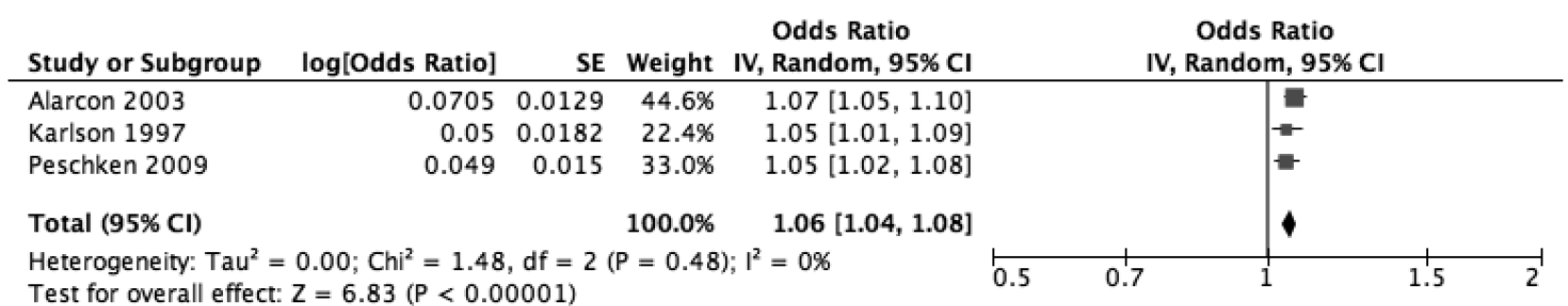

Figure 3. Forest plots depicting risk of damage accrual (measured by the SDI) with higher SLEDAI, BILAG, and SLAM scores. SDI: Systemic Lupus International Collaborating Clinics/American College of Rheumatology Damage Index; SLEDAI: Systemic Lupus Erythematosus Disease Activity Index; BILAG: British Isles Lupus Assessment Group; SLAM: SLE Activity Measure.

95\% CI $0.87-1.66)$ owing to high heterogeneity $\left(\mathrm{I}^{2}=66 \%\right.$; Figure 5). Possible causes included different population sources and small sample sizes (e.g., the LUMINA cohort with 352 patients versus a Norwegian hospital SLE cohort with 93 patients), and different sample sizes.
Several other studies evaluated the effect of disease damage (measured by the SDI) on mortality and damage accrual, with varying results (Table 1). For example, Appenzeller, et al found that SDI scores did not influence survival in a pediatric SLE cohort from Brazil ${ }^{47}$, while the

$$
\text { Personal non-commercial use only. The Journal of Rheumatology Copyright (c) 2018. All rights reserved. }
$$


Risk of mortality (HR) with higher damage scores as measured by the SDI.

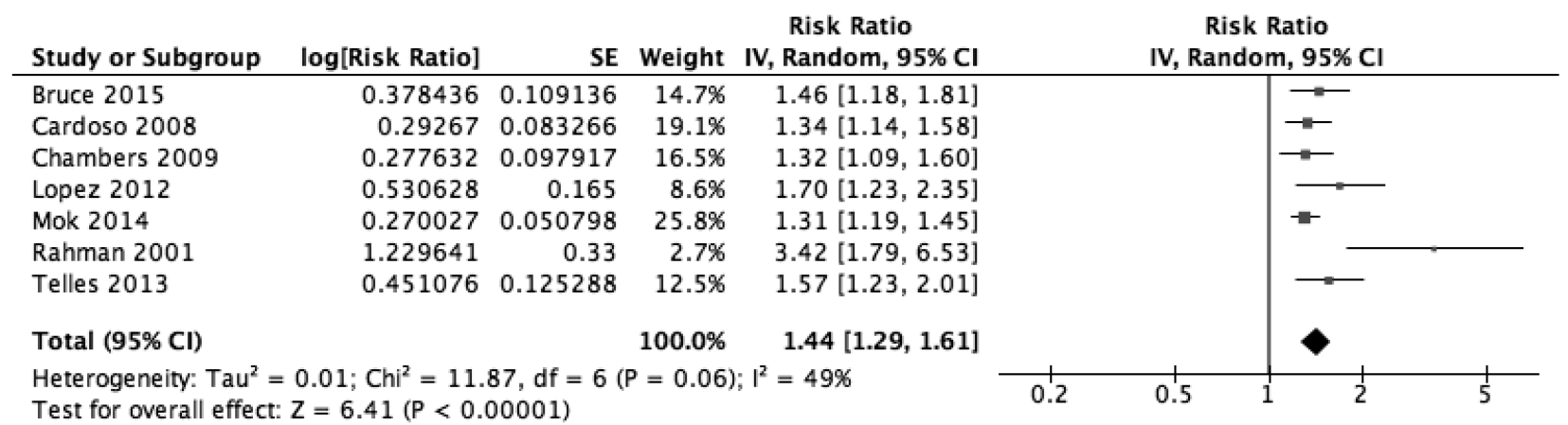

\section{Difference of past damage (measured by the SDI) between dead and living patients with SLE.}

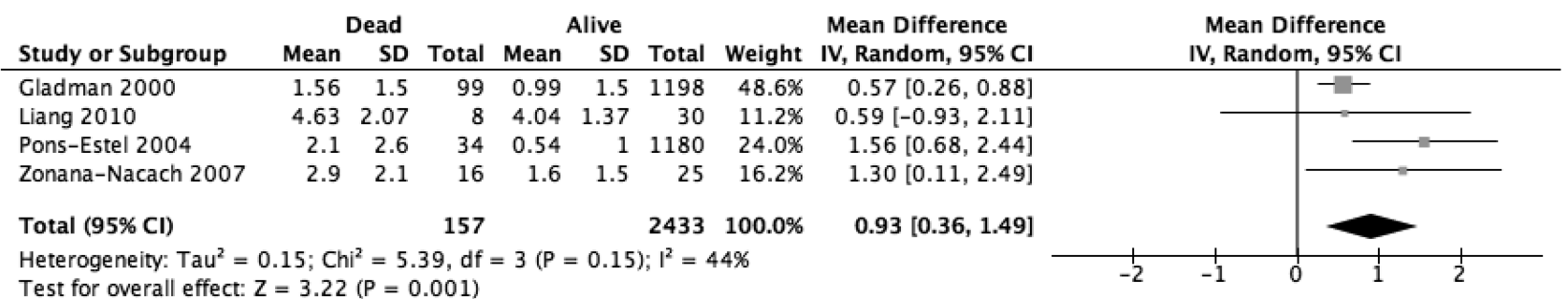

Figure 4. Forest plots associating damage with mortality in patients with SLE. SLE: systemic lupus erythematosus; SDI: Systemic Lupus International Collaborating Clinics/American College of Rheumatology Damage Index.

\section{Risk of damage from earlier damage.}

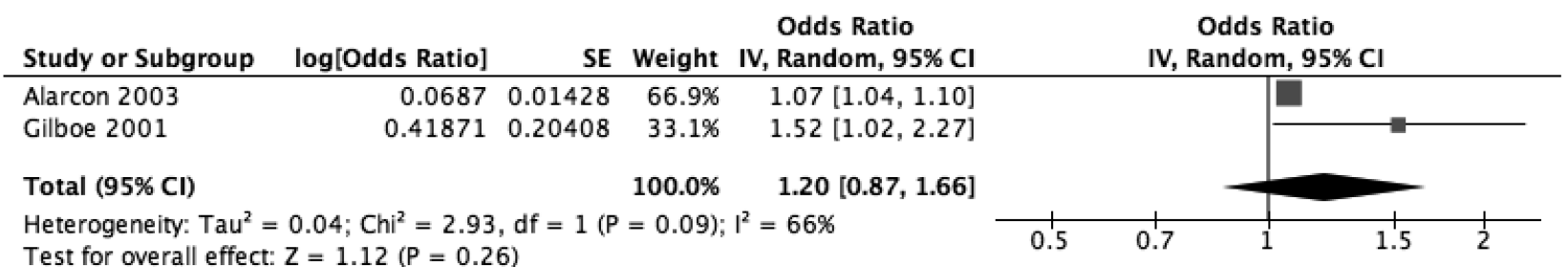

Figure 5. Forest plots depicting risk of damage (SDI) from past damage. SDI: Systemic Lupus International Collaborating Clinics/American College of Rheumatology Damage Index.

last measured SDI scores were higher in dead versus living pediatric patients with SLE in a Norwegian $\operatorname{cohort}^{24}$. A Swedish prospective inception cohort found that the SDI at 5 years postdiagnosis was predictive of survival and mortality up to a median of 7 years of followup ${ }^{57}$, while the Erlangen cohort from Nuremberg ${ }^{53}$ confirmed that an increase of 2 or more points of SDI from the first to the third year of disease was prognostic for mortality (RR 7.7, $p<0.0001)$. Renal damage at 1 year was predictive of death within 10 years of diagnosis in a Pakistani SLE cohort $^{58}$.

\section{DISCUSSION}

This systematic review suggests that disease activity and damage, as measured through various validated outcome measures, is overall associated with increased mortality and damage accrual. In particular, the effect of several different disease activity scores on the risk of mortality and damage accrual was consistently significant across the metaanalyses and largely confirmed by the independent studies. Overall, the risks of mortality and damage accrual were significantly higher with higher damage scores at baseline and over time, a result also supported by several individual studies. These 
results likely confirm what many SLE physicians have seen or demonstrated in their clinical practice and/or research settings. The multiple observational cohort studies suggest that disease activity and damage beget more damage and death. Therefore, physicians involved in SLE care should consider proper evaluation of disease activity and damage through a formalized method such as any of the disease activity and damage indices evaluated in our study (Supplementary Table 1, available with the online version of this article).

However, several issues arise from this systematic literature review that complicate this assumption. Despite identifying over 50 studies, the ability to evaluate the various outcome measures and pool studies for metaanalyses was challenging and limited largely to descriptive reporting. Reasons include the significant heterogeneity between cohorts and the objectives of each study, and differences in how and when specific outcome measures might have been collected in a particular cohort. Cohort descriptions varied in their detail, often with a wide range of disease activity or damage at baseline and followup. This may partially explain the variability in significant results when evaluating the effect of disease damage on mortality and damage accrual in the metaanalyses. Moreover, studies conflicted regarding the effect of damage on further damage accrual and even when comparing dead versus living patients based on differences in past damage. The effect of glucocorticoids and how they were analyzed in the studies may have contributed to varying effects of disease activity and damage on mortality and damage accrual. Great difficulty arose in separating out adult versus pediatric SLE, although attempts were made to include both in this review.

Regarding the completed metaanalyses, statistical heterogeneity (computed with $\mathrm{I}^{2}$ ) and heterogeneity in the characteristics of the studied cohorts were consistent challenges, reflecting among other things the unequal weight among studies within the analysis. For example, when evaluating the effect of higher disease activity scores on mortality, the combined studies included multiple international cohorts from China, Brazil, Europe, and Canada, and included hospitalized and outpatient groups and combined pediatric and adult patients, which may imply differences in SLE phenotypes and therefore disease severity.

This review was not meant to evaluate the validation and comparability of disease activity and damage metrics. However, it demonstrated that consistency and comparability exist across different metrics in evaluating for important outcomes in SLE. The choice of which measure to use will be influenced by many factors. Some important examples include feasibility in the clinical setting (e.g., time, paper vs electronic records, language used) to familiarity of clinic staff with a particular measure. Many components of the SLE disease activity and damage metrics are recorded in a good medical history and physical examination, which should be standard for SLE patients with the potential for multisystem disease. Moreover, adoption of standardized disease activity measures has already become integrated into rheumatology clinics beyond academic settings (e.g., the 28-joint count Disease Activity Score in RA, the Bath Ankylosing Spondylitis Disease Activity Score in SpA). The studies in our review were never designed to answer our specific PICO search strategy, and this likely contributed to the great heterogeneity seen in the results. Nevertheless, qualitatively the results of different studies based on different metrics of disease activity and damage, along with the results of the metaanalysis and the sensitivity analyses, were concordant. Clearly the results highlighted the effect of disease activity (at baseline and/or over time) on damage and mortality, and the effect of damage on mortality and further accrual of damage over time. A multicenter study to answer these questions with greater consistency in the metrics used to measure disease activity and damage would assist in addressing this more directly. Moreover, such a study might address how specific disease activity scores might be used in clinical practice, and what targets are appropriate in identifying low disease activity or remitted states, as is well-recognized in the defined disease activity score targets for RA.

This systematic literature review was conducted to inform a broader set of recommendations for the assessment of patients with SLE in Canada, focusing specifically on what to perform in the monitoring of our patients. This review confirmed that increased disease activity and damage, measured by validated metrics, were associated with further damage and increased mortality. This body of evidence was generated from studies using validated measures of disease activity and damage at baseline and on followup. Thus, it would be helpful to use validated metrics in the assessment and monitoring of SLE. The use of validated metrics enables scientists, trialists, industry people, and policy makers to qualify and evaluate the implication of a specific construct on other outcomes. When deciding on the use of a specific metric, one should consider its administrative (time, scoring, complexity) and cost burden, and the preparedness and skill of the assessor on the selected metric. Measurement of a health state (disease activity, damage) is essential in daily practice and research ${ }^{63}$, and Lord Kelvin stated, "when you can measure what you are speaking about, and express it in numbers, you know something about it; but when you cannot, your knowledge is of a meager and unsatisfactory kind ${ }^{64}$."

The results will be included as part of the evidence-to-decision table in upcoming recommendations, which will incorporate other important domains that must be considered when developing recommendations according to GRADE.

\section{ONLINE SUPPLEMENT}

Supplementary material accompanies the online version of this article.

\section{REFERENCES}

1. Yu C, Gershwin ME, Chang C. Diagnostic criteria for systemic

$$
\text { Personal non-commercial use only. The Journal of Rheumatology Copyright } \subset \text { (2018. All rights reserved. }
$$


lupus erythematosus: a critical review. J Autoimmun 2014; 48-49:10-3.

2. Sutton EJ, Davidson JE, Bruce IN. The Systemic Lupus International Collaborating Clinics (SLICC) Damage Index: a systematic literature review. Semin Arthritis Rheum 2013; 43:352-61.

3. Bissonauth A, Bernatsky S, Fortin P, Gladman D, Peschken C, Urowitz M, et al. Survey of practice patterns in the diagnosis and management of systemic lupus erythematosus in Canada [abstract 140]. Canadian Rheumatology Association meeting, Whistler, British Columbia. J Rheumatol 2014;41:1515.

4. Kiriakidou M, Cotton D, Taichman D, Williams S. Systemic lupus erythematosus. Ann Intern Med 2013;159:1.

5. Sedgwick P. Meta-analyses: what is heterogeneity? BMJ 2015;350:h1435.

6. Wells GA, Shea B, O'Connell D, Peterson J, Welch V, Losos M, et al. The Newcastle-Ottawa Scale (NOS) for assessing the quality of nonrandomized studies in meta-analyses. 2009. [Internet. Accessed July 6, 2018.] Available from: www.evidencebasedpublichealth.de /download/Newcastle_Ottowa_Scale_Pope_Bruce.pdf

7. Moher D, Liberati A, Tetzlaff J, Altman DG, PRISMA Group. Preferred reporting items for systematic reviews and meta-analyses: the PRISMA statement. PLoS Med 2009;6:e1000097.

8. Furie RA, Petri MA, Wallace DJ, Ginzler EM, Merrill JT, Stohl W, et al. Novel evidence-based systemic lupus erythematosus responder index. Arthritis Rheum 2009;61:1143-51.

9. Hay EM, Bacon PA, Gordon C, Isenberg DA, Maddison P, Snaith ML, et al. The BILAG index: a reliable and valid instrument for measuring clinical disease activity in systemic lupus erythematosus. Q J Med 1993;86:447-58.

10. Lopez R, Davidson JE, Beeby MD, Egger PJ, Isenberg DA. Lupus disease activity and the risk of subsequent organ damage and mortality in a large lupus cohort. Rheumatology 2012;51:491-8.

11. Stoll T, Sutcliffe N, Klaghofer R, Isenberg DA. Do present damage and health perception in patients with systemic lupus erythematosus predict extent of future damage?: a prospective study. Ann Rheum Dis 2000;59:832-5.

12. Stoll T, Sutcliffe N, Mach J, Klaghofer R, Isenberg DA. Analysis of the relationship between disease activity and damage in patients with systemic lupus erythematosus - a 5-yr prospective study. Rheumatology 2004;43:1039-44.

13. Bandeira M, Buratti S, Bartoli M, Gasparini C, Breda L, Pistorio A, et al. Relationship between damage accrual, disease flares and cumulative drug therapies in juvenile-onset systemic lupus erythematosus. Lupus 2006;15:515-20.

14. Becker-Merok A, Nossent HC. Damage accumulation in systemic lupus erythematosus and its relation to disease activity and mortality. J Rheumatol 2006;33:1570-7.

15. Bruce IN, O'Keeffe AG, Farewell V, Hanly JG, Manzi S, Su L, et al. Factors associated with damage accrual in patients with systemic lupus erythematosus: results from the Systemic Lupus International Collaborating Clinics (SLICC) Inception Cohort. Ann Rheum Dis 2015;74:1706-13.

16. Clowse ME, Grossman JM, Merrill JT, Askanase A, Dvorkin O, Lockshin MD, et al. Predictors of damage accrual over a 2 year period in a large multi-racial/ethnic lupus cohort [abstract]. Arthritis Rheum 2013;65 Suppl 10:S1244.

17. Feng X, Zou Y, Pan W, Wang X, Wu M, Zhang M, et al. Prognostic indicators of hospitalized patients with systemic lupus erythematosus: a large retrospective multicenter study in China. J Rheumatol 2011;38:1289-95.

18. Gilboe IM, Kvien TK, Husby G. Disease course in systemic lupus erythematosus: changes in health status, disease activity, and organ damage after 2 years. J Rheumatol 2001;28:266-74.

19. Hill D, Egger P, Qinggong F, Fang H, Petri M. Systemic lupus erythematosus disease activity during a 12-month period and risk of new onset organ system damage and/or death: observations in a single US academic medical center. Arthritis Rheum 2011;63 Suppl 10:S671

20. Ibañez D, Urowitz MB, Gladman DD. Summarizing disease features over time - part 2: the variability of SLEDAI-2K - does it help in predicting outcomes in SLE? Arthritis Rheum 2006;54 Supp1 9:S269.

21. Ibañez D, Gladman DD, Urowitz MB. Adjusted mean Systemic Lupus Erythematosus Disease Activity Index-2K is a predictor of outcome in SLE. J Rheumatol 2005;32:824-7.

22. Ibañez D, Gladman D, Urowitz M. Summarizing disease features over time: II. Variability measures of SLEDAI-2K. J Rheumatol 2007;34:336-40.

23. Liang CC, Lin HH, Wang IK, Kuo HL, Liu JH, Yeh HC, et al. Influence of predialysis comorbidity and damage accrual on mortality in lupus patients treated with peritoneal dialysis. Lupus 2010;19:1210-8.

24. Lilleby V, Flato B, Forre O. Disease duration, hypertension and medication requirements are associated with organ damage in childhood-onset systemic lupus erythematosus. Clin Exp Rheumatol 2005;23:261-9.

25. Lin H, Wei J, Tan C, Liu Y, Li Y, Li F, et al. Survival analysis of late-onset systemic lupus erythematosus: a cohort study in China. Clin Rheumatol 2012;31:1683-9.

26. Mikdashi J, Handwerger B. Predictors of neuropsychiatric damage in systemic lupus erythematosus: data from the Maryland lupus cohort. Rheumatology 2004;43:1555-60.

27. Mok CC, Ho CT, Wong RW, Lau CS. Damage accrual in southern Chinese patients with systemic lupus erythematosus. J Rheumatol 2003;30:1513-9.

28. Mok CC, To CH, Mak A. Neuropsychiatric damage in Southern Chinese patients with systemic lupus erythematosus. Medicine 2006;85:221-8.

29. Nossent JC. Course and prognostic value of Systemic Lupus Erythematosus Disease Activity Index in black Caribbean patients. Semin Arthritis Rheum 1993;23:16-21.

30. Nossent J, Kiss E, Rozman B, Pokorny G, Vlachoyiannopoulos P, Olesinska $\mathrm{M}$, et al. Disease activity and damage accrual during the early disease course in a multinational inception cohort of patients with systemic lupus erythematosus. Lupus 2010;19:949-56.

31. Petri M, Purvey S, Fang H, Magder LS. Predictors of organ damage in systemic lupus erythematosus: the Hopkins Lupus Cohort. Arthritis Rheum 2012;64:4021-8.

32. Pons-Estel BA, Catoggio LJ, Cardiel MH, Soriano ER, Gentiletti S, Villa AR, et al. The GLADEL Multinational Latin American Prospective Inception Cohort of 1,214 patients with systemic lupus erythematosus. Medicine 2004;83:1-17.

33. Ramirez Gomez LA, Uribe Uribe O, Osio Uribe O, Grisales Romero H, Cardiel MH, Wojdyla D, et al. Childhood systemic lupus erythematosus in Latin America. The GLADEL experience in 230 children. Lupus 2008;17:596-604.

34. Suarez-Larios LM, Faugier-Fuentes E, Maldonado-Velazquez R, Martine Martines MU. Prognostic factors associated with mortality in pediatric systemic lupus erythematosus (SLE), Ann Rheum Dis 2013;72:A382-707.

35. Telles RW, Lanna CC, Souza FL, Rodrigues LA, Reis RC, Ribeiro AL. Causes and predictors of death in Brazilian lupus patients. Rheumatol Int 2013;33:467-73.

36. Uziel Y, Gorodnitski N, Mukamel M, Padeh S, Brik R, Barash J, et al. Outcome of a national Israeli cohort of pediatric systemic lupus erythematosus. Lupus 2007;16:142-6.

37. Wu G, Jia X, Gao D, Zhao Z. Survival rates and risk factors for mortality in systemic lupus erythematosus patients in a Chinese center. Clin Rheumatol 2014;33:947-53. 
38. Wu JY, Yeh KW, Huang JL. Early predictors of outcomes in pediatric lupus nephritis: focus on proliferative lesions. Semin Arthritis Rheum 2014;43:513-20.

39. Zonana-Nacach A, Yanez P, Jimenez-Balderas FJ, Camargo-Coronel A. Disease activity, damage and survival in Mexican patients with acute severe systemic lupus erythematosus. Lupus 2007; 16:997-1000.

40. Alarcon GS, McGwin G, Bastian HM, Roseman J, Lisse J, Fessler $\mathrm{BJ}$, et al. Systemic lupus erythematosus in three ethnic groups. VII [correction of VIII]. Predictors of early mortality in the LUMINA cohort. LUMINA Study Group. Arthritis Rheum 2001;45:191-202.

41. Karlson EW, Daltroy LH, Lew RA, Wright EA, Partridge AJ, Fossel $\mathrm{AH}$, et al. The relationship of socioeconomic status, race, and modifiable risk factors to outcomes in patients with systemic lupus erythematosus. Arthritis Rheum 1997;40:47-56.

42. Nieves-Plaza M, Ortiz AP, Colon M, Molina MJ, Castro-Santana LE, Rodriguez VE, et al. Outcome and predictors of kidney disease progression in Puerto Ricans with systemic lupus erythematosus initially presenting with mild renal involvement. J Clin Rheumatol 2011;17:179-84.

43. Peschken CA, Katz SJ, Silverman E, Pope JE, Fortin PR, Pineau C, et al. The 1000 Canadian faces of lupus: determinants of disease outcome in a large multiethnic cohort. J Rheumatol 2009;36:1200-8.

44. Toloza SM, Roseman JM, Alarcon GS, McGwin G, Uribe AG, Fessler BJ, et al. Systemic lupus erythematosus in a multiethnic US cohort (LUMINA): XXII. Predictors of time to the occurrence of initial damage. Arthritis Rheum 2004;50:3177-86.

45. Shariati-Sarabi Z, Monzavi SM, Ranjbar A, Esmaily H, Etemadrezaie H. High disease activity is associated with high disease damage in an Iranian inception cohort of patients with lupus nephritis. Clin Exp Rheumatol 2013;31:69.

46. Alarcon GS, Roseman JM, McGwin G, Uribe A, Bastian HM, Fessler BJ, et al. Systemic lupus erythematosus in three ethnic groups. XX. Damage as a predictor of further damage. Rheumatology 2004;43:202-5.

47. Appenzeller S, Marini R, Costallat LT. Damage did not independently influence mortality in childhood systemic lupus erythematosus. Rheumatol Int 2005;25:619-24.

48. Cardoso CR, Signorelli FV, Papi JA, Salles GF. Initial and accrued damage as predictors of mortality in Brazilian patients with systemic lupus erythematosus: a cohort study. Lupus 2008; 17:1042-8.

49. Chambers SA, Allen E, Rahman A, Isenberg D. Damage and mortality in a group of British patients with systemic lupus erythematosus followed up for over 10 years. Rheumatology 2009;48:673-5.

50. Danila MI, Pons-Estel GJ, Zhang J, Vila LM, Reveille JD, Alarcon GS. Renal damage is the most important predictor of mortality within the damage index: data from LUMINA LXIV, a multiethnic US cohort. Rheumatology 2009;48:542-5.

51. Gladman DD, Goldsmith CH, Urowitz MB, Bacon P, Fortin P, Ginzler E, et al. The Systemic Lupus International Collaborating
Clinics/American College of Rheumatology (SLICC/ACR) damage index for systemic lupus erythematosus international comparison. J Rheumatol 2000;27:373-6.

52. Mak A, Mok CC, Chu WP, To CH, Wong SN, Au TC. Renal damage in systemic lupus erythematosus: a comparative analysis of different age groups. Lupus 2007;16:28-34.

53. Manger K, Manger B, Repp R, Geisselbrecht M, Geiger A, Pfahlberg A, et al. Definition of risk factors for death, end stage renal disease, and thromboembolic events in a monocentric cohort of 338 patients with systemic lupus erythematosus. Ann Rheum Dis 2002;61:1065-70.

54. Mok CC, Kwok RC, Yip PS. Effect of renal disease on the standardized mortality ratio and life expectancy of patients with systemic lupus erythematosus. Arthritis Rheum 2013;65:2154-60.

55. Mok CC, Tse SM, Ho LY, To CH. Factors associated with damage accrual and survival in Chinese patients with systemic lupus erythematosus (SLE): A prospective cohort analysis of 747 patients. Arthritis Rheumatol 2014;66 Suppl 11:S1152.

56. Mok CC, Ho LY, Chan KL, To CH. Effect of renal damage on extra-renal organ damage and mortality in patients with systemic lupus erythematosus (SLE): A longitudinal cohort study of 756 patients. Arthritis Rheum 2013;65 Suppl 10:S262.

57. Nived O, Jonsen A, Bengtsson AA, Bengtsson C, Sturfelt G. High predictive value of the Systemic Lupus International Collaborating Clinics/American College of Rheumatology damage index for survival in systemic lupus erythematosus. J Rheumatol 2002;29:1398-400.

58. Rabbani MA, Habib HB, Islam M, Ahmad B, Shah SM, Tahir S, et al. Early renal damage assessed by the SLICC/ACR damage index is predictor of severe outcome in lupus patients in Pakistan. Lupus 2010;19:1573-8.

59. Rahman P, Gladman DD, Urowitz MB, Hallett D, Tam LS. Early damage as measured by the SLICC/ACR damage index is a predictor of mortality in systemic lupus erythematosus. Lupus 2001;10:93-6

60. Stoll T, Seifert B, Isenberg DA. SLICC/ACR Damage Index is valid, and renal and pulmonary organ scores are predictors of severe outcome in patients with systemic lupus erythematosus. Br J Rheumatol 1996;35:248-54.

61. Katz P, Trupin L, Rush S, Yazdany J. Longitudinal validation of the Brief Index of Lupus Damage. Arthritis Care Res 2014;66:1057-62.

62. Higgins JP, Altman DG, Gotzsche PC, Juni P, Moher D, Oxman AD, et al. The Cochrane Collaboration's tool for assessing risk of bias in randomised trials. BMJ 2011;343:d5928.

63. Luca NL, Feldman BM. Disease activity measures in paediatric rheumatic diseases. [Internet. Accessed July 9, 2018.] Available from: www.hindawi.com/journals/ijr/2013/715352/

64. Thomson W. Electrical units of measurement. Popular Lectures. 1883, page 73. [Internet. Accessed July 9, 2018.] Available from: ia902702.us.archive.org/25/items/popularlecturesa01kelvuoft/popul arlecturesa01kelvuoft.pdf 